\title{
Genetic Overlap between Holoprosencephaly and Kallmann Syndrome
}

\author{
K. Vaaralahtia,b T. Raivio ${ }^{a, b} \quad$ R. Koivu ${ }^{a, b} \quad$ L. Valanne ${ }^{c}$ E.-M. Laitinen ${ }^{a, b}$ \\ J. Tommiska ${ }^{a, b}$ \\ anstitute of Biomedicine/Physiology, University of Helsinki, ${ }^{b}$ Children's Hospital and ${ }^{\mathrm{C}}$ Helsinki Medical Imaging \\ Center, Helsinki University Central Hospital, Helsinki, Finland
}

\section{Key Words}

Holoprosencephaly $\cdot$ Kallmann syndrome $\cdot$ Septo-optic dysplasia

\begin{abstract}
Patients with Kallmann syndrome (KS; congenital hypogonadotropic hypogonadism and decreased/absent sense of smell), septo-optic dysplasia (SOD), or holoprosencephaly (HPE) reportedly have midline defects. In this study, we investigate a genetic overlap between KS, SOD, and HPE. Nineteen subjects (18 males, 1 female) with KS and without mutations in the known KS genes were screened for mutations in SOX2, SHH, SIX3, TGIF1, TDGF1, FOXH1, GLI2, and GLI3. One male carried 2 heterozygous missense changes, one in $S I X 3$ (c.428G >A, p.G143D) and the other in GLI2 (c.2509G >A, p.E837K). Both of these genes have been implicated in the etiology of HPE and neither of these changes were present in 200 control subjects. Other variants found among the subjects were known polymorphisms. KS and HPE may display a genetic overlap. The involvement of genes implicated in the etiology of midline defects in patients with KS warrants further studies.

Copyright $\odot 2012$ S. Karger AG, Basel
\end{abstract}

(C) 2012 S. Karger AG, Basel

1661-8769/12/0031-0001\$38.00/0

Fax +41613061234 E-Mail karger@karger.ch www.karger.com
Accessible online at: www.karger.com/msy
Kallmann syndrome (KS; MIM 147950), a combination of congenital hypogonadotropic hypogonadism (HH; MIM 146110) and decreased/absent sense of smell, has traditionally been thought to result from disturbed intrauterine migration of gonadotropin releasing hormone $(\mathrm{GnRH})$ neurons from the olfactory placode to the hypothalamus [Schwanzel-Fukuda et al., 1989; Cariboni and Maggi, 2006]. Anatomically, KS can be defined by olfactory bulb aplasia and accumulation of $\mathrm{GnRH}$ neurons outside the brain, together with the premature termination of olfactory and terminal nerve fibers. It has been recently shown that deficient migration of GnRH neurons is also a feature in forebrain formation defects [Texeira et al., 2010]. Patients with KS usually lack puberty and associated phenotypic features include midline defects such as cleft lip/palate, renal agenesis, agenesis of the corpus callosum, and absent olfactory bulbs [Seminara et al., 1998]. The genes involved in the etiology of KS are KAL1 [Franco et al., 1991; Legouis, 1991], FGFR1 [Dode et al., 2003], FGF8 [Falardeau et al., 2008], PROK2 [Dode et al., 2006; Pitteloud et al., 2007a], PROKR2 [Dode et al., 2006; Pitteloud et al., 2007a], CHD7 [Kim et al., 2008] and WDR11 [Kim et al., 2010]. Midline defects are also encountered in septo-optic dysplasia (SOD; MIM 182230) [Dattani, 1998] and holoprosencephaly (HPE;

Dr. Johanna Tommiska

Institute of Biomedicine/Physiology, University of Helsinki, Biomedicum Helsinki Haartmaninkatu 8, PO Box 63

FI-00014 Helsinki (Finland)

Tel. +358 919125 286, E-Mail johanna.tommiska@ helsinki.fi 
MIM 236100), a complex brain malformation affecting both the forebrain and the face [Demyer and Zeman, 1963].

SOD is a highly heterogeneous condition with variable phenotypes including midline and forebrain abnormalities, and optic nerve and pituitary hypoplasia [Dattani, 1998]. Most instances of SOD are sporadic, and several etiologies, including alcohol abuse of the mother during pregnancy, have been suggested to account for the pathogenesis of the condition. However, an increasing number of familial cases have been described with mutations identified in transcription factor genes such as SOX2, HESX1, SOX3, and OTX2. These transcription factors are essential for normal forebrain development, and defects in these genes could account for the features observed in SOD and other midline disorders [Webb and Dattani, 2010; McCabe et al., 2011a]. In fact, genetic overlap between SOD and congenital HH has been suggested previously [Sato et al., 2007; Stark et al., 2011].

HPE results from incomplete cleavage of the prosencephalon that occurs between the 18th and the 28th day of gestation. Three ranges of increasing severity are described: lobar, semilobar, and alobar HPE [Demyer and Zeman, 1963; Cohen, 2006]. Children with HPE may have endocrine disorders such as diabetes insipidus, adrenal hypoplasia, hypogonadism, thyroid hypoplasia, and growth hormone deficiency. Midline defects observed in HPE include cyclopia, proboscis, median or bilateral cleft lip/palate in severe forms, ocular hypotelorism, or solitary median maxillary central incisor in minor forms. As in KS, many genes associated with the condition have been identified so far (including $\mathrm{SHH}$, SIX3, TGIF1, TDGF1, FOXH1, and GLI2) [Dubourg et al., 2007].

In addition to midline defects, highly variable phenotype spectrum with incomplete penetrance and variable expressivity of the mutations are observed in all 3 syndromes (KS, SOD, and HPE) [Dode et al., 2003; Lazaro et al., 2006; Raivio et al., 2009; McCabe et al., 2011a]. Also, a molecular genetic diagnosis is attained only in approximately $30 \%$ of the KS and HPE patients [Dubourg et al., 2007; Bianco and Kaiser, 2009; Semple and Topaloglu, 2010] and in less than 1\% of SOD cases [Webb and Dattani, 2010]. This suggests an existence of several other candidate genes or environmental factors underlying these syndromes. Recently, KS and HPE have been suggested as allelic syndromes, as at least mutations in FGF8 appear to underlie both conditions [Arauz et al., 2010; McCabe et al., 2011b]. Accordingly, we have recently found mutations in FGFR1 among patients with SOD or combined pituitary hormone deficiencies [Raivio et al., 2012].

In the current work, we further investigated the genetic overlap between KS, HPE, and SOD by screening 19 KS subjects without mutations in the known KS genes for mutations in SOX2, SHH, SIX3, TGIF1, TDGF1, FOXH1, GLI2, and GLI3.

\section{Subjects and Methods}

\section{Subjects}

The clinical features of the $18 \mathrm{KS}$ male subjects have been reported in Laitinen et al. [2011]. In short, all adult subjects were diagnosed based on (1) absent or incomplete pubertal development by the age of 18 years, (2) low-circulating basal sex steroid levels in association with inappropriately low or normal gonadotropin levels, and subnormal or normal response to GnRH stimulation test, (3) otherwise normal anterior pituitary function, (4) no organic cause for their condition, and (5) anosmia or hyposmia as assessed by 40 -item smell testing (University of Pennsylvania Smell Identification Test, UPSIT, Sensonics Inc, Haddon Heights, N.J., USA) and/or absent or rudimentary olfactory bulbs visualized in MRI. The following MRI protocol was used to visualize the olfactory bulbs, sulci, and inner ears (corresponding sequences in 1.5 and 3 tesla units): axial $5 \mathrm{~mm}$ T2 FSE and FLAIR images of the whole brain, coronal T2 FSE with $3 \mathrm{~mm}$ slice thickness starting from the anterior surface of the frontal lobe, 3D MPR sagittal images $(1 \times 1 \mathrm{~mm})$ covering the whole head with coronal reconstructions, and $3 \mathrm{D} \mathrm{T} 2$-weighted thin slice axial images (CISS, DRIVE, voxel size $0.3-0.5 \mathrm{~mm} \times 3$ ) from the region of the inner ear. No contrast medium was used. In addition to adult patients, 3 12-18 year-old patients with unequivocal signs of severe congenital HH (history of cryptorchidism and/or micropenis), absent pubertal development, and anosmia/hyposmia were enrolled. One female KS patient with a history of spontaneous puberty followed by secondary amenorrhea, congenital anosmia, absent olfactory bulbs in the MRI, and low estradiol (E2) in the setting of normal gonadotropin levels (single measurements), thus representing mild GnRH deficiency [Shaw et al., 2011], was also included. Two male subjects had CHARGE syndrome-associated features (1: cleft lip and palate, unilateral microphthalmia and coloboma, bilateral hearing impairment, left facial nerve palsy, cup-shaped ears, upper body muscular atrophy, and hypoplastic semicircular canals; 2 : cup-shaped ears and upper body muscular atrophy). None of the subjects have been found to carry mutations in the 7 genes known to underlie KS (KAL1, FGFR1, FGF8, PROK2, PROKR2, CHD7, and WDR11), and no intragenic deletions were found in CHD7 or FGFR1 multiplex ligation-dependent probe amplification assays (MLPAs, MRC-Holland, Amsterdam, The Netherlands). The Ethics Committee of the Helsinki University Central Hospital approved the study protocol, appropriate permissions were provided from each university hospital in Finland, and all subjects obtained and signed the written consent.

\section{Mutation Screening}

Genomic DNA from peripheral blood leukocytes was extracted, and the coding exons and exon-intron boundaries of 8 genes 
[SOX2 (MIM 184429; RefSeq NM_003106.3, gi: 325651854) [Williamson et al., 2006], SHH (MIM 600725; RefSeq NM_000193.2, gi:21071042) [Belloni et al., 1996], SIX3 (MIM 603714; RefSeq NM_005413.3, gi:261878476) [Wallis and Muenke, 1999], TGIF1 (MIM 602630; RefSeq NM_170695.2, gi:28178842) [Gripp et al., 2000], TDGF1 (MIM 187395; RefSeq NM_003212.3, gi:261878476) [de la Cruz et al., 2002], FOXH1 (MIM 603621; RefSeq NM_003923.2, gi:208973255) [Roessler et al., 2008], GLI2 (MIM 165230; RefSeq NM_005270.4, gi:190343019) [Roessler et al., 2003], and GLI3 (MIM 165240; RefSeq NM_000168.5, gi:195947346) [Kang et al., 1997; Engelen et al., 2011] were PCR amplified and screened by direct sequencing. PCR products were purified with ExoSAP-IT treatment (Amersham Biosciences, Piscataway, N.J., USA), and sequenced using the ABI BigDyeTerminator Cycle Sequencing Kit (v3.1) and ABI Prism 3730xl DNA Analyzer automated sequencer (Applied Biosystems, Foster City, Calif., USA). The sequences were aligned and read with Sequencher ${ }^{\circledR} 4.9$ software (Gene Codes Corporation, AnnArbor, Mich., USA). All primer sequences and PCR conditions are available upon request. Mutations were confirmed from a second PCR product. Mutation nomenclature is according to the guidelines of the Human Genome Variation Society [Wildeman et al., 2008] and was verified using the Mutalyzer software (http://www. mutalyzer.nl/2.0/).

\section{Results}

\section{Mutation Screening}

In 1 male patient, we found 2 heterozygous missense changes, one in SIX3 (c.428G >A, p.G143D) and the other in GLI2 (c.2509 G>A, p.E837K). This patient had a small testis volume $(1.5 \mathrm{ml})$, absent sense of smell, no synkinesia, or detectable midline defects such as cleft lip or palate. The MRI revealed absent olfactory bulbs and partially hypoplastic olfactory sulci. These changes in SIX3 and GLI2 were not present in 200 control subjects from the same geographical region, but the GLI2 E837K was reported in the dbSNP database (http://www.ncbi.nlm. nih.gov/SNP/) with 1 entry from the 1000 Genome project (rs193090538). According to MutPred (http://mutpred. mutdb.org/), a probability of a deleterious mutation is 0.5 for the SIX3 variant and 0.284 for the GLI2 variant [Li et al., 2009], but both of them were predicted to be possibly damaging by PolyPhen2 (http://genetics.bwh.harvard. edu/pph2/) [Adzhubei et al., 2010]. Other variants found were known polymorphisms.

\section{Discussion}

$\mathrm{KS}$, SOD, and HPE are genetically heterogeneous disorders with multiple genes involved identified so far. Yet, the majority of patients remain without molecular genet-

Kallmann Syndrome, Septo-Optic

Dysplasia, and Holoprosencephaly ic diagnosis. Although the phenotype spectrum of patients varies from severe to asymptomatic, midline defects are reported in most cases. We investigated the genetic overlap between KS, HPE, and SOD by screening 19 KS subjects without mutations in the known KS genes for mutations in SOX2, SHH, SIX3, TGIF1, TDGF1, FOXH1, GLI2, and GLI3.

We found 2 heterozygous missense changes, c. $428 \mathrm{G}>\mathrm{A}$ (p.G143D) in SIX3 and c.2509G >A (p.E837K) in GLI2, not present in 200 controls, in 1 male KS patient. Although these rare variants were predicted possibly damaging by PolyPhen2, there is no evidence that they are disease causing. In addition, the GLI2 E837K has also been reported in the dbSNP with 1 entry from the 1000Genome project. The patient had anosmia, absent olfactory bulbs and hypoplastic olfactory sulci bilaterally, severe $\mathrm{HH}$ with bilateral cryptorchidism and micropenis, but no other additional phenotypic features: he neither displayed midline anomalies (such as cleft lip and palate, high-arched palate, or dental agenesis), nor post axial polydactyly. A central incisor was not observed. The MRI of this patient did not reveal any signs consistent with HPE. Even truncating GLI2 mutations have been described in families with variable pituitary hormone deficiencies, midline defects, and absence of signs of HPE [Franca et al., 2010]. Incomplete penetrance of the mutations and variable phenotype including subtle microform of HPE have also been reported in patients with SIX3 defects [Solomon et al., 2010]. In addition, additive effects of the mutations and/or di/oligogenic inheritance have been shown in congenital HH [Pitteloud et al., 2007b; Sykiotis et al., 2010]. However, this has not been observed in HPE, and it is suggested that more subtle genetic and environmental interactions are more likely to contribute to the phenotype variability in HPE than mutations in more than 1 gene [Roessler et al., 2012]. Unfortunately, the patient's parents are deceased, so their DNA samples were not available for testing. The mother had had juvenile rheumatoid arthritis and delayed menarche at 16 years of age. The parents did not display any distinct syndromes, and a sibling (half-brother from the mother's side) was also devoid of midline defects. The pubertal development of the half-brother was normal. MRIs or other imaging studies of the relatives are not available.

Two of our KS patients have CHARGE syndrome-associated features, but no mutations in $C H D 7$, shown to underlie both CHARGE and KS [Kim et al., 2008]. It has been recently shown that Chd7 and Sox 2 interact physically and cooperate to regulate a set of common target genes mutated in several human syndromes [Engelen et 
al., 2011]. In addition, very recently, a frameshift mutation in SOX2 leading to anophthalmia/microphthalmia in siblings was also found in their mother who only manifested isolated HH [Stark et al., 2011]. To the best of our knowledge, this is the first study where SOX2 has been analyzed in a series of patients with congenital $\mathrm{HH}$. The fact that no mutations were found, however, suggests that SOX2 is not a significant $\mathrm{HH}$ gene, at least when no family history of anophthalmia/microphthalmia is present. However, larger patient series, including patients with normosmic congenital $\mathrm{HH}$, need to be investigated to further elucidate the role of $S O X 2$ in congenital $\mathrm{HH}$.

Our conclusion is that mutations in SOX2, SHH, SIX3, TGIF1, TDGF1, FOXH1, GLI2, and GLI3 are not a com- mon cause for KS in Finland. However, 1 patient harbored a novel missense change in SIX 3 and another rare missense variant in GLI2, suggesting the possibility of a genetic overlap between KS and HPE. As our patient series is small, this finding needs to be confirmed by studies in different patient groups and populations.

\section{Acknowledgements}

This work was supported by the Academy of Finland, the Foundation for Paediatric Research, the Helsinki University Central Hospital Research Funds, the Sigrid Juselius Foundation, Helsinki University Research Funds, and the Emil Aaltonen Foundation.

\section{References}

-Adzhubei IA, Schmidt S, Peshkin L, Ramensky VE, Gerasimova A, et al: A method and server for predicting damaging missense mutations. Nat Methods 7:248-249 (2010).

-Arauz RF, Solomon BD, Pineda-Alvarez DE, Gropman AL, Parsons JA, et al: A hypomorphic allele in the FGF8 gene contributes to holoprosencephaly and is allelic to gonadotropin-releasing hormone deficiency in humans. Mol Syndromol 1:59-66 (2010).

- Belloni E, Muenke M, Roessler E, Traverso G, Siegel-Bartelt J, et al: Identification of Sonic hedgehog as a candidate gene responsible for holoprosencephaly. Nat Genet 14:353-356 (1996).

Bianco SD, Kaiser UB: The genetic and molecular basis of idiopathic hypogonadotropic hypogonadism. Nat Rev Endocrinol 5:569-576 (2009).

-Cariboni A, Maggi R: Kallmann's syndrome, a neuronal migration defect. Cell Mol Life Sci 63:2512-2526 (2006)

Cohen MM Jr: Holoprosencephaly: clinical, anatomic, and molecular dimensions. Birth Defects Res A Clin Mol Teratol 76:658-673 (2006).

- Dattani MT, Martinez-Barbera JP, Thomas PQ, Brickman JM, Gupta R, et al: Mutations in the homeobox gene HESX1/Hes $x 1$ associated with septo-optic dysplasia in human and mouse. Nature Genet 19:125-133 (1998).

de la Cruz JM, Bamford RN, Burdine RD, Roessler E, Barkovich AJ, et al: A loss-of-function mutation in the CFC domain of TDGF1 is associated with human forebrain defects. Hum Genet 110:422-428 (2002).

Demyer W, Zeman W: Alobar holoprosencephaly (arhinencephaly) with median cleft lip and palate: clinical, electroencephalographic and nosologic considerations. Confin Neurol 23:1-36 (1963).
Dodé C, Levilliers J, Dupont JM, De Paepe A, Le Dû $\mathrm{N}$, et al: Loss-of-function mutations in FGFR1 cause autosomal dominant Kallmann syndrome. Nat Genet 33:463-465 (2003).

Dodé C, Teixeira L, Levilliers J, Fouveaut C, Bouchard P, et al: Kallmann syndrome: mutations in the genes encoding prokineticin-2 and prokineticin receptor-2. PLoS Genet 2:e175 (2006).

Dubourg C, Bendavid C, Pasquier L, Henry C, Odent S, David V: Holoprosencephaly. Orphanet J Rare Dis 2:8 (2007).

Engelen E, Akinci U, Bryne JC, Hou J, Gontan C, et al: Sox 2 cooperates with Chd7 to regulate genes that are mutated in human syndromes. Nat Genet 43:607-611 (2011).

Falardeau J, Chung WC, Beenken A, Raivio T, Plummer L, et al: Decreased FGF8 signaling causes deficiency of gonadotropin-releasing hormone in humans and mice. J Clin Invest 118:2822-2831 (2008).

França MM, Jorge AA, Carvalho LR, Costalonga EF, Vasques GA, et al: Novel heterozygous nonsense GLI2 mutations in patients with hypopituitarism and ectopic posterior pituitary lobe without holoprosencephaly. J Clin Endocrinol Metab 95:E384-E391 (2010).

Franco B, Guioli S, Pragliola A, Incerti B, Bardoni B, et al: A gene deleted in Kallmann's syndrome shares homology with neural cell adhesion and axonal path-finding molecules. Nature 353:529-536 (1991).

- Gripp KW, Wotton D, Edwards MC, Roessler E, Ades L, et al: Mutations in TGIF cause holoprosencephaly and link NODAL signalling to human neural axis determination. Nat Genet 25:205-208 (2000).

Kang S, Graham JM Jr, Olney AH, Biesecker LG: GLI3 frameshift mutations cause autosomal dominant Pallister-Hall syndrome. Nat Genet 15:266-268 (1997).
Kim HG, Kurth I, Lan F, Meliciani I, Wenzel W, et al: Mutations in $C H D 7$, encoding a chromatin-remodeling protein, cause idiopathic hypogonadotropic hypogonadism and Kallmann syndrome. Am J Hum Genet 83:511519 (2008).

Kim HG, Ahn JW, Kurth I, Ullmann R, Kim HT, et al: WDR11, a WD protein that interacts with transcription factor EMX1, is mutated in idiopathic hypogonadotropic hypogonadism and Kallmann syndrome. Am J Hum Genet 87:465-479 (2010).

Laitinen EM, Vaaralahti K, Tommiska J, Eklund E, Tervaniemi M, et al: Incidence, phenotypic features and molecular genetics of Kallmann syndrome in Finland. Orphanet J Rare Dis 6:41 (2011)

- Lazaro L, Dubourg C, Pasquier L, Le Duff F, Blayau M, et al: Phenotypic and molecular variability of the holoprosencephalic spectrum. Am J Med Genet A 129A:21-24 (2004).

Legouis R, Hardelin JP, Levilliers J, Claverie JM, Compain S, et al: The candidate gene for the $\mathrm{X}$-linked Kallmann syndrome encodes a protein related to adhesion molecules. Cell 67:423-435 (1991).

Li B, Krishnan VG, Mort ME, Xin F, Kamati KK, et al: Automated inference of molecular mechanisms of disease from amino acid substitutions. Bioinformatics 25:2744-2750 (2009).

McCabe MJ, Alatzoglou KS, Dattani MT: Septooptic dysplasia and other midline defects: the role of transcription factors: HESX1 and beyond. Best Pract Res Clin Endocrinol Metab 25:115-124 (2011a).

McCabe MJ, Gaston-Massuet C, Tziaferi V, Gregory LC, Alatzoglou KS, et al: Novel FGF8 mutations associated with recessive holoprosencephaly, craniofacial defects, and hypothalamo-pituitary dysfunction. J Clin Endocrinol Metab 96:E1709-E1718 (2011b). 
Pitteloud N, Zhang C, Pignatelli D, Li JD, Raivio $\mathrm{T}$, et al: Loss-of-function mutation in the prokineticin 2 gene causes Kallmann syndrome and normosmic idiopathic hypogonadotropic hypogonadism. Proc Natl Acad Sci USA 104:17447-17452 (2007a).

- Pitteloud N, Quinton R, Pearce S, Raivio T, Acierno J, at al: Digenic mutations account for variable phenotypes in idiopathic hypogonadotropic hypogonadism. J Clin Invest 117: 457-463 (2007b).

Raivio T, Sidis Y, Plummer L, Chen H, Ma J, et al: Impaired fibroblast growth factor receptor 1 signaling as a cause of normosmic idiopathic hypogonadotropic hypogonadism. J Clin Endocrinol Metab 94:4380-4390 (2009).

Raivio T, Avbelj M, McCabe MJ, Romero CJ, Dwyer AA, et al: Genetic overlap in Kallmann syndrome, combined pituitary hormone deficiency, and septo-optic dysplasia. J Clin Endocrinol Metab (2012), E-pub ahead of print.

Roessler E, Du YZ, Mullor JL, Casas E, Allen WP, et al: Loss-of-function mutations in the human GLI2 gene are associated with pituitary anomalies and holoprosencephaly-like features. Proc Natl Acad Sci USA 100:1342413429 (2003).

Roessler E, Ouspenskaia MV, Karkera JD, Vélez JI, Kantipong A, et al: Reduced NODAL signaling strength via mutation of several pathway members including FOXH1 is linked to human heart defects and holoprosencephaly. Am J Hum Genet 83:18-29 (2008).
Roessler E, Vélez JI, Zhou N, Muenke M: Utilizing prospective sequence analysis of $\mathrm{SHH}$, ZIC2, SIX3 and TGIF in holoprosencephaly probands to describe the parameters limiting the observed frequency of mutant gene×gene interactions. Mol Genet Metab 105:658-664 (2012).

Sato N, Kamachi Y, Kondoh H, Shima Y, Morohashi $\mathrm{K}$, et al: Hypogonadotropic hypogonadism in an adult female with a heterozygous hypomorphic mutation of SOX2. Eur J Endocrinol 156:167-171 (2007).

-Schwanzel-Fukuda M, Bick D, Pfaff DW: Luteinizing hormone-releasing hormone (LHRH)expressing cells do not migrate normally in an inherited hypogonadal (Kallmann) syndrome. Mol Brain Res 6:311-326 (1989).

Seminara SB, Hayes FJ, Crowley WF Jr: Gonadotropin-releasing hormone deficiency in the human (idiopathic hypogonadotropic hypogonadism and Kallmann's syndrome): pathophysiological and genetic considerations. Endocr Rev 19:521-539 (1998).

Semple RK, Topaloglu AK: The recent genetics of hypogonadotrophic hypogonadism - novel insights and new questions. Clin Endocrinol (Oxf) 72:427-435 (2010).

- Shaw ND, Seminara SB, Welt CK, Au MG, Plummer L, et al: Expanding the phenotype and genotype of female GnRH deficiency. J Clin Endocrinol Metab 96:566-576 (2011).
Solomon BD, Mercier S, Vélez JI, Pineda-Alvarez DE, Wyllie A, et al: Analysis of genotypephenotype correlations in human holoprosencephaly. Am J Med Genet C Semin Med Genet 154C:133-141 (2010).

-Stark Z, Storen R, Bennetts B, Savarirayan R, Jamieson RV: Isolated hypogonadotropic hypogonadism with SOX2 mutation and anophthalmia/microphthalmia in offspring. Eur J Hum Genet 19:753-756 (2011)

-Sykiotis GP, Plummer L, Hughes VA, Au M, Durrani S, et al: Oligogenic basis of isolated gonadotropin-releasing hormone deficiency. Proc Natl Acad Sci USA 107:15140-15144 (2010).

Teixeira L, Guimiot F, Dodé C, Fallet-Bianco C, Millar RP, et al: Defective migration of neuroendocrine GnRH cells in human arrhinencephalic conditions. J Clin Invest 120: 3668-3672 (2010).

-Wallis DE, Muenke M: Molecular mechanisms of holoprosencephaly. Mol Genet Metab 68: 126-138 (1999).

Webb EA, Dattani MT: Septo-optic dysplasia. Eur J Hum Genet 18:393-397 (2010).

-Wildeman M, van Ophuizen E, den Dunnen JT, Taschner PE: Improving sequence variant descriptions in mutation databases and literature using the Mutalyzer sequence variation nomenclature checker. Hum Mutat 29: 6-13 (2008)

-Williamson KA, Hever AM, Rainger J, Rogers RC, Magee A, et al: Mutations in SOX2 cause anophthalmia-esophageal-genital (AEG) syndrome. Hum Mol Genet 15:1413-1422 (2006). 